\title{
Editorial
}

\section{The worlds of information}

On reviewing the contents of this issue, I was struck by the rather eclectic mixture presented to our readers in this and other issues of Information Services $\&$ Use. The wide variety of subjects, and national origins reminds me of why I find my job and this information world so fascinating.

Consider this single issue. We have contributions dealing with specific database design (Kar and Siddiqui), management support (Hämäläinen), behavioral aspects of information workers (Nkereuwem), futurism for database publishers (Lawrence), full-text management (Cuadra), and socio-political aspects of information processing (Koenig)!

This mixture validates the permeating nature of information in modern society of course, but it also attests to the highly interactive processes that are at work.

The national origins of the authors appearing in Volume $10 / 5$ presents the information world in yet another dimension. India, Finland, Nigeria and the United States present us with additional contextual dimensions.

As we approach the end of 1990 the winds of change blowing through our social, political, cultural, and technical environment are of gale force. All of these factors will further perturb the information "climate" and present your Editors with new challenges.

We look forward to presenting in these pages a modicum of shelter from inclement weather, a perspective on the information environment, some navigational aids and a balanced view of the worlds of information.

A.W. Elias 